\title{
Correction to: Abrupt Decrease of Wintertime Cold Nights in Korea in the Late 1980s
}

\author{
Yeong-Eun Yoo ${ }^{1} \cdot$ Seok-Woo Son ${ }^{1}$ (D) $\cdot$ Jong-Hwa Lee ${ }^{1} \cdot$ Seung-Ki Min ${ }^{2}$ \\ Published online: 2 July 2019 \\ (C) Korean Meteorological Society and Springer Nature B.V. 2019
}

\section{Correction to: Asia-Pacific J Atmos Sci (2019) 55:31-39 https://doi.org/10.1007/s13143-018-0057-4}

The original version of this article unfortunately contains some mistakes. Due to a typesetting mistake, spaces between words had been inadvertently removed in several places. As the missing spaces had been overlooked during proof correction, the article was unfortunately published without adding the spaces. The publisher apologizes for any inconvenience caused by this mistake.

The complete corrected article is repeated below.

\begin{abstract}
The decadal change of wintertime cold nights in Korea and its relationship with atmospheric circulation are investigated. Wintertime cold nights, defined as the nights when the daily minimum temperatures are lower than their $10^{\text {th }}$ percentile, are calculated for 10 Korean Meteorological Administration (KMA) stations over the period of 1960-2015. In all stations, the number of cold nights sharply decreased in the late 1980s. A step-wise change is largely due to the reduction in long-lasting events persisting for three consecutive nights or longer. It is further found that the cold nights before and after the late 1980s are associated with different synoptic and
\end{abstract}

The online version of the original article can be found at https://doi.org/ 10.1007/s13143-018-0057-4

Seok-Woo Son

seokwooson@snu.ac.kr

1 School of Earth and Environmental Sciences, Seoul National University, Gwanak-gu, Seoul 08826, South Korea

2 Division of Environmental Science and Engineering, Pohang University of Science and Technology, Pohang, South Korea large-scale circulation patterns. While the pre-1980 events are maintained by an east-west dipolar sea level pressure (SLP) pattern with an anomalous high over Northern China and an anomalous low in the western North Pacific, the post-1990 events are characterized by a north-south dipole with an enhanced impact from Siberia and a reduced influence from the western North Pacific. In accordance with these synoptic patterns, the Pacific-related climate variability indices, such as the Pacific-North American (PNA) teleconnection index, exhibit a negligible interannual relationship with the number of cold nights in the post-1990. These results suggest that the wintertime cold extremes over Korea in recent decades are influenced by different circulation patterns from those in the 1970s and 1980s.

Keywords Cold nights $\cdot$ Korea $\cdot$ Climate indices

\section{Introduction}

Surface air temperature has steadily increased over the last several decades. Both mean and extreme temperatures have changed, although their trends are not necessarily the same. For example, the long-term trends of temperature extremes, such as the $10^{\text {th }}$-percentile daily minimum temperature (TN), can be stronger than those of the daily mean temperature (e.g., Franzke 2013).

Weather and climate extremes, including heat waves and anomalously cold nights, can cause enormous damages to the ecosystem and human society. As such, understanding their long-term variability and the associated physical mechanism(s) is of the utmost importance. To quantify their global changes, previous studies have utilized various global observations (Kiktev et al., 2003; Alexander et al. 2006; Moberg et al. 2006; IPCC 2012; Min et al., 2013; Kim et al. 2015, 2016). Regional perspectives have also been explored by using both 
global and regional datasets (Qian et al. 2007; Fischer et al. 2012; Lee et al. 2012; Zhang et al. 2012; Yang et al. 2014).

In Korea, several studies have attempted to quantify longterm variability of temperature extremes as recently reviewed by Min et al. (2015). Lee et al. (2013a) and Kim et al. (2014), among others, documented that the long-term trends of temperature extremes in Korea are spatially inhomogeneous and asymmetric between warm and cold extremes. It is shown that the $5^{\text {th }}$-percentile daily TN trends are stronger than the $95^{\text {th }}$ percentile trends. This result indicates a rapid decrease in cold extremes but a slow increase in warm extremes. Heo and Lee (2006) and Choi et al. (2008) more quantitatively showed that the number of cold extremes has significantly decreased over the observational period.

A series of studies also showed that temperature extremes in Korea have changed nonlinearly. In particular, it is shown that the daily $\mathrm{TN}$ and the number of $10^{\text {th }}$-percentile dailymean temperature events have abruptly decreased in the late 1980s (Ryoo et al. 2004; Lee et al. 2011, 2013b; Choi et al. 2016). This peculiar change has been qualitatively explained by regional circulation changes (Im and Ahn 2004; Choi and Kim 2015). Ryoo et al. (2004) and Lee et al. (2013b) related this phenomenon to the mean flow change associated with the Arctic Oscillation, the East Asia winter monsoon, and the Aleutian Low. Lee et al. (2013b) further suggested that the weakening of the Siberian High and Aleutian Low in the late 1980s has likely led to the reduced cold extremes during the same period of time.

Although these studies highlighted nonlinear changes in the wintertime daily TN and cold extremes in Korea, their nature has not been well addressed. To update and extend these findings, the present study revisits the long-term variability of wintertime cold extremes in Korea by considering 10 weather stations operated by the Korea Meteorological Administration (KMA). Unlike the previous studies that examined multiple climate extremes, only cold nights are analyzed in this study to explore the associated circulation changes in details. Regional circulation changes as well as largescale circulation changes are considered to better understand the linear and nonlinear changes of wintertime cold nights.

This paper is structured as follows. The data and methodology are presented in Section 2, the long-term variability and trend of wintertime cold nights are documented in Section 3. The differences in the atmospheric circulation patterns associated with cold nights before and after the abrupt change are examined in Section 4. This study is then concluded with a brief summary in Section 5.

\section{Data and Methods}

To analyze changes in cold extremes, the daily TN of KMA stations are used. The stations that provide long-term records from 1960/61 to 2014/15 (55 winters) are considered. After excluding re-located stations and stations with missing data, a total of 10 stations (i.e., Gangneung, Seoul, Chupungryeong, Daegu, Jeonju, Ulsan, Gwangju, Busan, Mokpo, and Yeosu) are chosen for this study.

A cold night is defined as a night when the daily TN anomaly is lower than its $10^{\text {th }}$ percentile. To define the anomaly, the daily climatology, estimated from the 1981-2010 timeseries, is removed from the daily $\mathrm{TN}$ record. The number of cold nights (e.g., 5-day long event is counted as five nights) and the number of cold night "events" (e.g., 5-day long event is counted as one event) are calculated for each station in each winter. The duration of cold night event is also computed by counting the number of consecutive cold nights. The intensity of cold nights is defined by averaging the $\mathrm{TN}$ anomalies for each event.

The number, intensity, and duration of cold night event are calculated for all 10 stations. The multi-station mean statistics are then defined by averaging them. As a representative station, analysis results are mainly discussed for Seoul.

The significance of the decadal change in cold night statistics is evaluated by using the Lepage test (Lepage 1971; Kwon et al. 2005). Given the two time series of $X=\left(x_{1}, x_{2}, \cdots, x_{N}\right)$ and $Y=\left(y_{1}, y_{2}, \cdots, y_{N}\right)$ with $N$ elements, one can compose a time series of $X Y=\left(x_{1}, \cdots, x_{N}, y_{1}, \cdots, y_{N}\right)$ by combining the elements of $X$ and $Y$. The statistic of the Lepage test is then defined as

$H K=\frac{[W-E(W)]^{2}}{V(W)}+\frac{[A-E(A)]^{2}}{V(A)}$,

where $W$ and $A$ are the Wilcoxon-Mann-Whitney test statistic (Mann and Whitney 1947) and the AnsariBradley test statistic (Ansari and Bradley 1960) for testing the changes in the mean and variance of the two groups, $X$ and $Y$. $\mathrm{E}(W), \mathrm{E}(A), \mathrm{V}(W)$ and $\mathrm{V}(A)$ represent the expectation and variance of $W$ and $A$, respectively. If the Lepage statistic $(\mathrm{HK})$ is greater than its $95 \%$ or $99 \%$ confidence level, one can conclude that there is a significant difference in timeseries $X$ and $Y$.

The Lepage statistic (HK) has the advantage of testing the changes in both the mean and the variance between the two groups by combining $W$ and $A$. In this study, both $x$ and $y$ are the number of cold nights at a given winter, and $X$ and $Y$ are their respective timeseries before and after the reference year $t_{c}$. For the evaluation window of $N=10$ years, the two timeseries are set to $\mathrm{X}$ $\left[t_{c}-N, t_{c}-1\right]$ and $\mathrm{Y}\left[t_{c}, t_{c}+N-1\right]$. A larger $N$ is used for detecting the changes in long-term variability. For example, the change in the number of cold nights across $1975 / 76$ December-January-February (DJF) is evaluated by setting $X$ as the timeseries of the number of cold 
nights over 10 years from 1965/66 DJF to 1974/75 DJF and $Y$ as that from $1975 / 76$ DJF to $1984 / 85$ DJF.

To examine synoptic and large-scale circulation patterns, Japanese 55-year Reanalysis (JRA-55; Onogi et al. 2007) daily and monthly data are used. Specifically, surface air temperature, sea level pressure (SLP), geopotential height and horizontal wind fields are analyzed. Only 18 UTC (03KST) datasets are used to reveal atmospheric circulation pattern at night. Large-scale circulation patterns are also examined by considering 16 climatic indices provided by National Centers for Environmental Prediction (NCEP) Climate Diagnostic Center (CDC) and Climate Prediction Center (CPC), as listed in Table 1. In addition to these standard indices, the Siberian High index (SHI; Panagiotopoulos et al. 2005) and the East Asian winter monsoon index (EAWMI; Jhun and Lee 2004) are considered (Table 1). All indices are based on daily mean values.

\section{Wintertime Cold Nights in Korea}

The number of cold nights, the number of cold night events, and the intensity of cold nights in Korea from 1960/61 to 2014/15 DJF are shown in Fig. 1. It is clear that the number of cold nights abruptly decreased around the late 1980s (Fig. 1a-b). Cold nights occurred more frequently with a weak decadal variability during the 1960s and 1970s, after which they became less frequent with a slight increase in the 2010s. This result is largely consistent with the findings of previous studies (Ryoo et al. 2004; Lee et al. 2011, 2013b; Choi et al. 2016).

This abrupt decrease in the number of cold nights is observed at all $10 \mathrm{KMA}$ stations (grey) including Seoul (red). More importantly, this finding is not sensitive to the definition as similar changes are also found for other percentiles (i.e., the $5^{\text {th }}$ - and $20^{\text {th }}$-quantile, not shown). When the number of cold night events, averaged across all KMA stations, is classified in terms of their durations, the most significant changes are found in cold night events lasting for three consecutive nights or longer (Fig. 1b). Although relatively short events (i.e., lasting a night or two) also show a reduced frequency in the late 1980 s, their change is statistically insignificant. This result implies that the abrupt decrease in the number of cold nights is dominated by the reduced occurrence of long-lasting events. Unlike the number of events, the mean intensity of individual events does not change much (Fig. 1c), indicating that the intensity itself is stable compared with the frequency change.

To estimate the changing point of the number of cold nights, the Lepage test (Section 2) is applied to each 10-year moving window (Fig. 2). The result shows the optimal changing point at 1986/87 DJF. This supports a transition in the number of cold nights
Table 1 Climate variability indices used in this study. Most indices are based on NCEP/CPC indices

\begin{tabular}{lll}
\hline & Climate Variability Index & source \\
\hline AMOI & Atlantic Multidecadal Oscillation Index & NCEP/CDC \\
AOI & Arctic Oscillation Index & NCEP/CPC \\
EAWMI & East Asia Winter Monsoon Index & Jhun et al. 2004 \\
ESOI & Equatorial Southern Oscillation Index & NCEP/CPC \\
ESLI & Equatorial Eastern Pacific SLP Index & NCEP/CPC \\
GML & Global Mean Land Ocean Temperature Index & NCEP/CDC \\
MEI & Multivariate ENSO Index & NCEP/CDC \\
NAOI & North Atlantic Oscillation Index & NCEP/CPC \\
NPI & North Pacific Index & NCEP/CPC \\
ONI & Oceanic Nino Index & NCEP/CPC \\
PDOI & Pacific Decadal Oscillation Index & NCEP/CDC \\
PNAI & Pacific/North American Pattern Index & NCEP/CPC \\
SHI & Siberian High Index & Panagiotopoulos et al. 2005 \\
SOI & Southern Oscillation Index & NCEP/CPC \\
TNA & Tropical Northern Atlantic Index & NCEP/CDC \\
TSA & Tropical Southern Atlantic Index & NCEP/CDC \\
WHW & Western Hemisphere Warm Pool Index & NCEP/CDC \\
WPI & West Pacific Index & NCEP/CPC \\
\hline
\end{tabular}



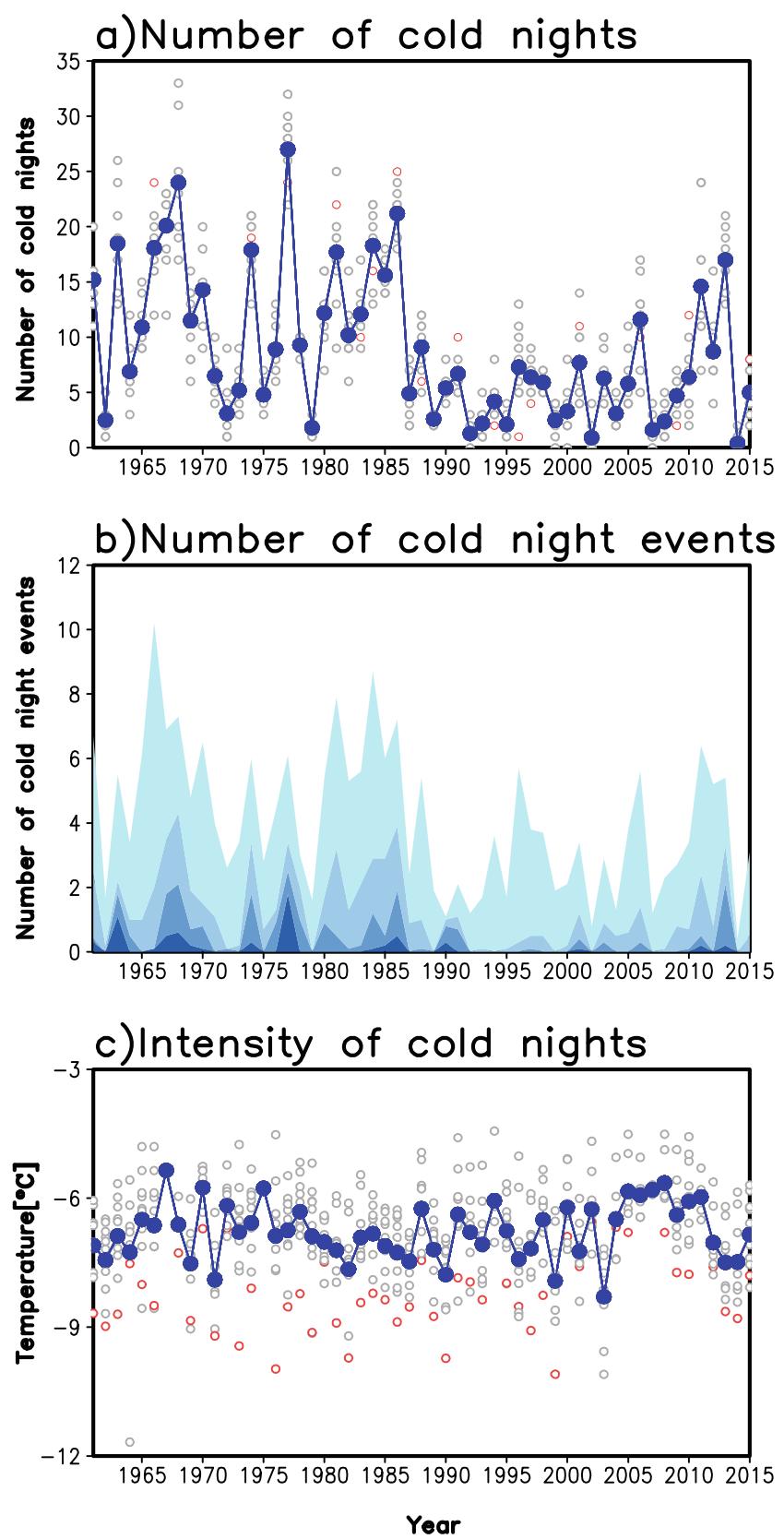

Fig. 1 Timeseries of (a) the number of cold nights, (b) the number of cold night events, and (c) the intensity of cold nights for $10 \mathrm{KMA}$ stations from 1960/61 to 2014/15 winters. In (a, c), grey and red dots indicate individual stations and Seoul. Blue dots denote 10 station mean. In (b), each color represents the number of cold night events that persist more than one night (light blue), three consecutive nights (sky blue), five consecutive nights (blue), and seven consecutive nights or longer (dark blue)

in Korea during the late 1980s (Lee et al. 2011). Although not shown, essentially the same results are obtained when the analysis window $(N)$ is varied from 10 to 15 years.

Are the abrupt decadal changes in the number of cold nights associated with the mean and variance of the daily TN anomaly? To address this issue, the probability distribution function (PDF) of the daily TN in Period 1 (1960/61-1985/86; P1 hereafter) and Period 2 (1990/91-2014/15; P2 hereafter) are compared in Fig. 3a and c. Only 10 stations mean TN and Seoul TN are shown. The 4 years from 1986/87-1989/90 are excluded here as a transition period. As a reference, the timeseries of the seasonal mean $\mathrm{TN}$ is also shown in Fig. $3 b$ and $d$.

From $\mathrm{P} 1$ to $\mathrm{P} 2$, the mean temperature anomaly increased from $-1.04^{\circ} \mathrm{C}$ to $0.12^{\circ} \mathrm{C}$ (Fig. 3a). However, the daily standard deviation decreased from $1.17^{\circ} \mathrm{C}$ to $0.90^{\circ} \mathrm{C}$. Most importantly, the PDF of the daily TN anomaly shows a greater shift towards the right on the left tail than on the right tail. This implies that the lower percentiles increased more rapidly than the upper percentiles from P1 to P2 (Fig. 3a). Although this asymmetry is important, the time evolution of the number of cold nights (blue dots in Fig. 1a) is still highly associated with that of the daily TN anomaly (Fig. 3b). Their correlation is -0.89 . This result suggests that the occurrence of cold nights is significantly influenced by the mean flow in each year, as suggested in Ryoo et al. (2004) and Lee et al. (2013b). In other words, the abrupt decrease in the number of cold nights in Korea is at least in part caused by largescale atmospheric circulation changes. Essentially the same results are found for all KMA stations (Fig. 3c and $\mathrm{d}$ ).

\section{Changes in Synoptic and Large-Scale Circulation Patterns}

The synoptic and large-scale circulation anomalies associated with cold nights are examined in this section. To identify their possible changes across the late 1980s, composite and statistical analyses are conducted not only for the whole analysis period but also for P1 and P2. Only the cold night events that occurred in Seoul are considered as representative events (Figs. 1 and 3 ).

Figure 4 illustrates the climatological SLP and 850$\mathrm{hPa}$ horizontal winds and their differences between P1 and P2. The climatological SLP displays a typical pattern of the East Asia winter monsoon that consists of the Siberian High and Aleutian Low (Fig. 4a). Across the late 1980s, the Siberian High slightly weakened and the Aleutian Low moved northeastward (Fig. 4b). These changes represent a weakening of the East Asia winter monsoon, likely inducing anomalous southerlies with a reduced number of cold nights during P2. 


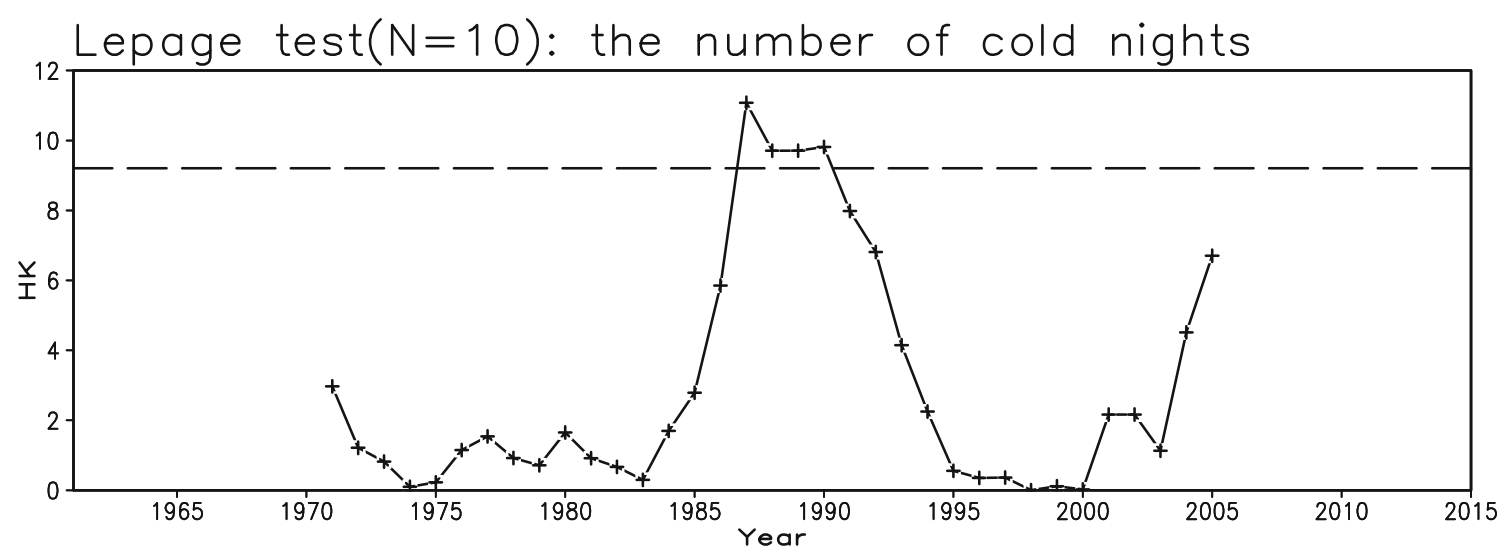

Fig. 2 Timeseries of Lepage-test statistics for the number of cold nights averaged over $10 \mathrm{KMA}$ stations. Long dashed line indicates the significant value for Lepage test at the $99 \%$ confidence level

Figure 5 illustrates the composite weather maps on the coldest night of each cold night event in Seoul during the whole period and the two sub-periods. A coldest night of cold night event is defined as a night when the lowest TN is observed. For the whole period, positive and negative SLP anomalies (shaded) are identified from Eastern China to the Korean Peninsula (Fig. 5a). This east-west dipolar SLP pattern results in anomalous northerlies, causing cold nights in Korea. With strong negative $300-\mathrm{hPa}$ geopotential height anomalies (contoured) to the west of the negative SLP anomalies and positive geopotential height anomalies to the northwest of the positive SLP anomalies, the overall circulation pattern is characterized by a baroclinic weather system. While a similar pattern is found in P1 (Fig. 5b), the cold nights in P2 accompany much stronger SLP anomalies around northern Siberia (near the Arctic sea) than those in P1. These SLP patterns are accompanied by $300-\mathrm{hPa}$ geopotential height anomalies that are shifted northeastward to northern Siberia (compare Fig. 5b and c). Note that the positive anomalies around northern Siberia show a quasi-barotropic structure. More importantly, the $300-\mathrm{hPa}$ geopotential height pattern is not a purely east-west dipole in $\mathrm{P} 2$ but is rather close to a north-south-oriented dipole pattern (Fig. 5c). This result suggests that the cold nights in $\mathrm{P} 1$ and $\mathrm{P} 2$ are associated with different synoptic patterns.

The circulation differences between P1 and P2 cold night events are further quantified by comparing the
a)TN PDF (10 KMA station)

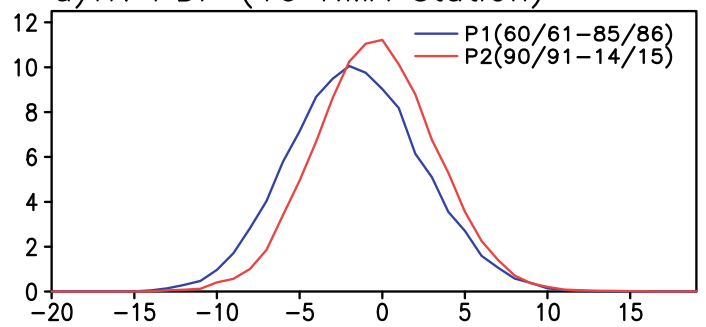

c)TN PDF (Seoul)

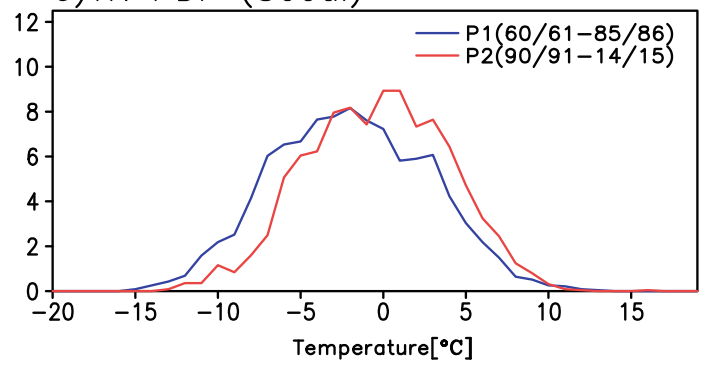

b)TN Timeseries (10 KMA station)

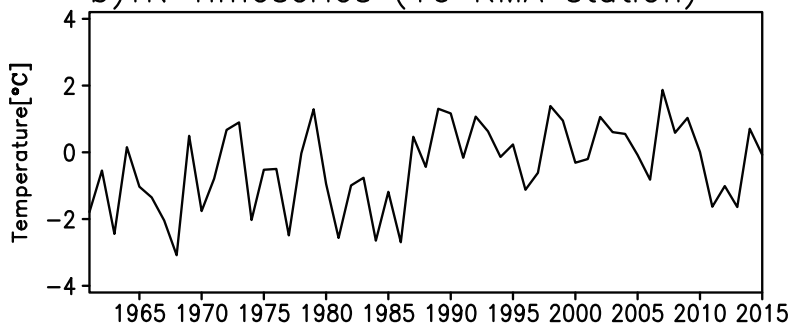

d)TN Timeseries (Seoul)

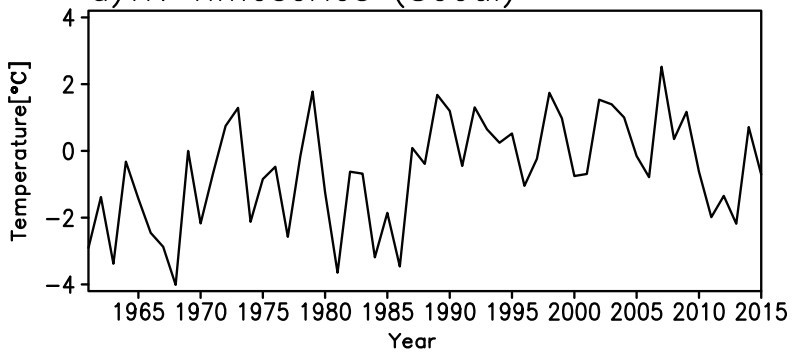

Fig. 3 a Probability distribution function of daily minimum temperature (TN) anomalies for P1 (blue) and P2 (red) periods and (b) timeseries of TN anomalies averaged over 10 KMA stations. $\mathbf{c}, \mathbf{d}$ same as $(\mathbf{a}, \mathbf{b})$ but for Seoul 

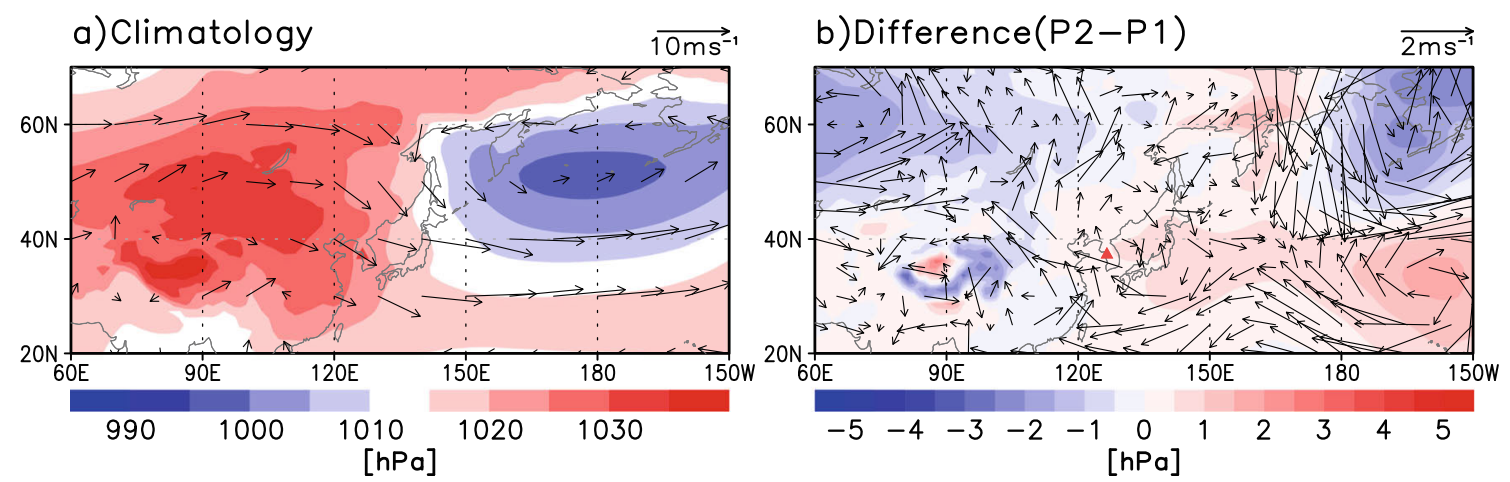

Fig. 4 a Climatology of SLP (shaded) and 850-hPa horizontal winds (vector), and (b) their differences between P1 and P2 periods. Red triangle denotes Seoul

frequencies of the dipole patterns (Table 2). Here, the dipole index is defined as the difference in the geopotential height anomalies at $300 \mathrm{hPa}$ between the two regions. Based on Fig. 5, the east-west dipole index is defined by the difference between $\mathrm{R} 1\left(75^{\circ} \mathrm{E}-110^{\circ} \mathrm{E}\right.$, $\left.55^{\circ} \mathrm{N}-65^{\circ} \mathrm{N}\right)$ and $\mathrm{R} 3\left(120^{\circ} \mathrm{E}-145^{\circ} \mathrm{E}, 35^{\circ} \mathrm{N}-45^{\circ} \mathrm{N}\right)$. Likewise, the north-south dipole index is defined by the difference between $\mathrm{R} 2\left(100^{\circ} \mathrm{E}-130^{\circ} \mathrm{E}, 65^{\circ} \mathrm{N}-80^{\circ} \mathrm{N}\right)$ and R3 $\left(120^{\circ} \mathrm{E}-145^{\circ} \mathrm{E}, 35^{\circ} \mathrm{N}-45^{\circ} \mathrm{N}\right)$. Note that these regions do not strictly represent east-west or north-south dipoles since latitude or longitude bands are not fixed. As such, these indices need to be understood in a relative sense.

If the east-west dipole index (R1-R3) is larger than the north-south dipole index (R2-R3), the circulation anomalies are set to the east-west dipole pattern. The opposite case is set to the north-south dipole pattern. As summarized in Table 2, the east-west and northsouth dipole indices for P1 cold night events are $55.6 \%$ and $35.5 \%$, respectively. In contrast, they are $43.3 \%$ and $53.3 \%$ for P2 cold night events. This result clearly indicates that the east-west dipole pattern is dominant during $\mathrm{P} 1$, whereas the north-south dipole pattern is more important during $\mathrm{P} 2$.

Changes in atmospheric circulation patterns between P1 and P2 cold night events are also evident in the interannual variability of cold nights. Figure 6 illustrates the correlation map between the number of cold nights in Seoul and the $850-\mathrm{hPa}$ temperature anomalies (T850) and SLP during DJF. The negative correlations in Fig. 6a indicate that cold nights often accompany cold temperature anomalies at $850 \mathrm{hPa}$. The negatively-correlated region is quite broad, covering Siberia, China, Korea, and Japan. During P1, the negatively-correlated region resembles that of the whole period with a slightly reduced areal extent (Fig. 6b). However, this is not the case in P2, in which the negatively-correlated region is shifted poleward to Eastern Russia, Northern China, and Korea (Fig. 6c).

A similar result is also found in the SLP field. Consistent with the synoptic pattern shown in Fig. 5a, positive and negative correlations about the Korea Peninsula are observed in Fig. 6d. This implies that wintertime cold nights become more frequent when the Siberian High and the Aleutian Low are prominent around the Korean Peninsula. A qualitatively similar pattern appears in P1 (Fig. 6e). However, the P2 correlation pattern is again different from the $\mathrm{P} 1$ correlation pattern (Fig. 6f). In particular, no significant correlation appears in the western North Pacific. This result suggests that the Aleutian Low has limited impacts on the interannual variability of the number of cold nights in P2.

To identify the teleconnection patterns associated with P1 and P2 cold night events, the correlation is also computed against various climate variability indices (Fig. 7a). As listed in Table 1, a total of 18 climate variability indices are considered, but only the indices with a statistically significant correlation are presented here. For the whole analysis period, AOI, SHI, and EAWMI exhibit strong correlations to the number of cold nights in Seoul. The correlation coefficients in both $\mathrm{P} 1$ and $\mathrm{P} 2$ are statistically significant at the $99 \%$ confidence level despite the EAWMI correlation becoming weak in P2. However, the correlations of the Pacific-related indices (e.g., NPI, PDOI, PNAI, and WPI) exhibit different results between P1 and P2. Although they play an important role in the interannual variability of the number of cold nights in P1, their impacts become insignificant in P2. Instead North Atlantic Oscillation Index (NAOI) becomes important in P2. Although the related dynamics remains to be determined, this result accentuates that the interannual variability of the number of cold nights in $\mathrm{P} 2$ are different from that in $\mathrm{P} 1$. 

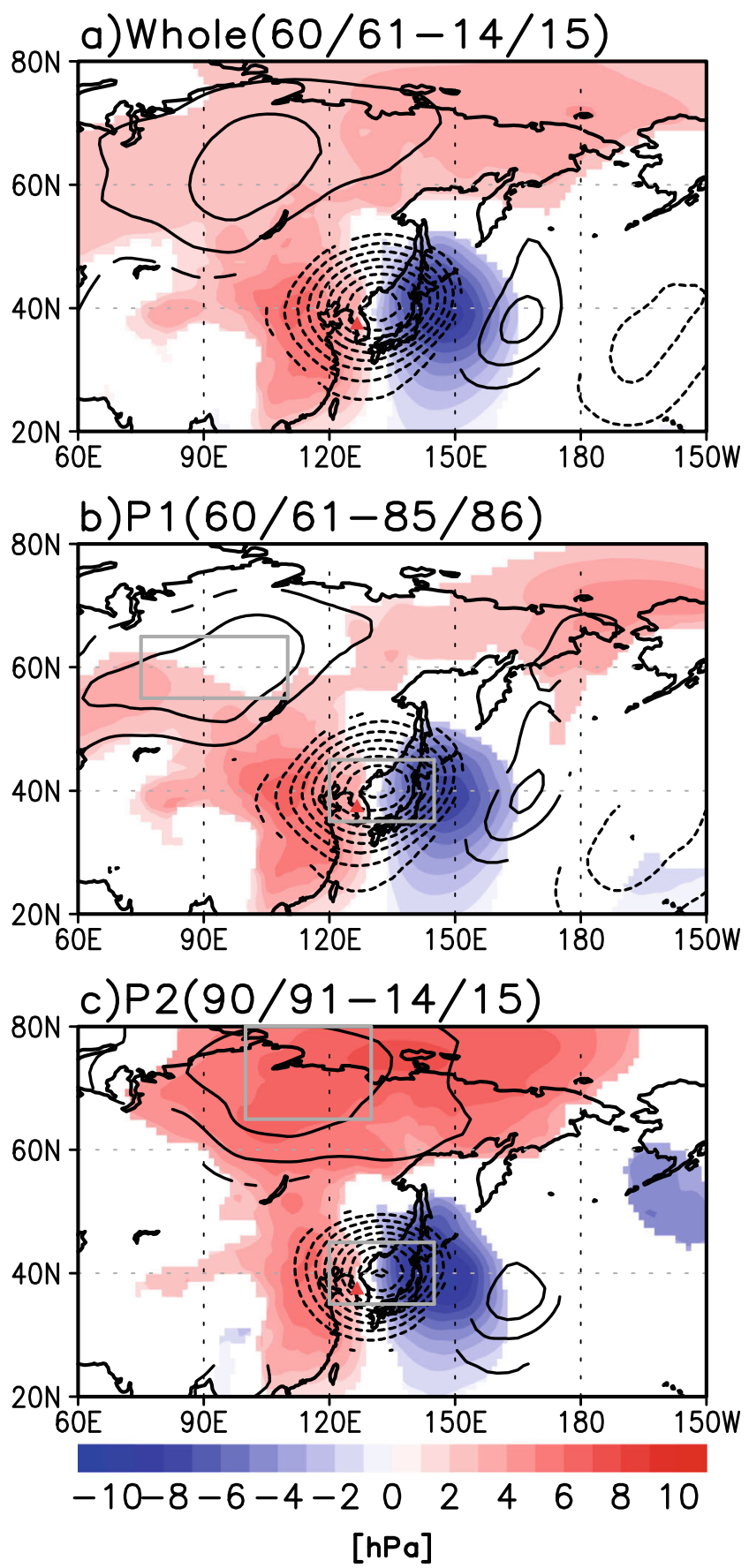

Fig. 5 SLP (shaded) and 300-hPa geopotential height anomalies (contour; interval of $30 \mathrm{gpm}$ ) for cold night events in Seoul: (a) the whole analysis period, (b) P1 and (c) P2 periods. Only the values that are statistically significant at the $99 \%$ confidence level are presented. Grey boxes in $(\mathbf{b}, \mathbf{c})$ denote the regions that are used to define dipole indices in Table 2. Red triangle denotes Seoul

This result is consistent with the reduced influence of the western North Pacific climate variability on the number of cold nights in Korea during P2 (Fig. 6f). While the occurrence of wintertime cold nights over
Table 2 The number of cold night events associated with west-east or north-south dipole patterns during $\mathrm{P} 1$ and $\mathrm{P} 2$ periods

\begin{tabular}{lll}
\hline & P1 (60/61-85/86) & P2 (90/91-14/15) \\
\hline west-east dipole & $69(55.6 \%)$ & $26(43.3 \%)$ \\
north-south dipole & $44(35.5 \%)$ & $32(53.3 \%)$ \\
\hline
\end{tabular}

the Korean Peninsula is associated with the Arctic Oscillation, Siberian High, and East Asia winter monsoon on interannual time scale, the influence of Pacificrelated climate variability has diminished dramatically in the recent decades.

The above results describe the different synoptic and large-scale characteristics of cold nights in P1 and P2. They do not explain the cause of abrupt decrease of the number of cold nights in the late 1980s. Not surprisingly, both EAWMI and SHI show a sharp decline in the late 1980s (Fig. 7b; see also Ryoo et al. (2004) and Lee et al. (2013b)). However, none of the climate indices examined in this study exhibit a significant change around the late 1980s. For instance, all Pacific-related climate indices do not show systematic changes in the late 1980s (Fig. 7c). This result may suggest that the decadal change of the number of cold nights itself is likely caused by regional circulation changes. To better understand this change, further analyses are needed.

\section{Summary and Discussion}

Changes in the frequency and intensity of cold nights in Korea are quantitatively evaluated from 1960/61 DJF to $2014 / 15$ DJF. It is found that the number of cold nights drastically decreased across the late 1980 s, which is consistent with a sudden increase in the daily TN (Ryoo et al. 2004; Lee et al. 2011, $2013 \mathrm{~b}$ ). On average, the number of cold nights before the late 1980s was about 4 nights per month. The number of cold nights became about 1.5 nights per month afterward with a slight increase in the 2010s. This abrupt decrease in the frequency of cold nights is primarily due to the reduction of long-lasting events that persist for three consecutive nights or longer. Unlike this frequency change, no significant change is observed in the intensity of cold nights.

To understand the physical processes associated with cold night events, the synoptic weather patterns are compared between the pre-1980s (P1) and the post1990s (P2). The P1 cold night events are typically 

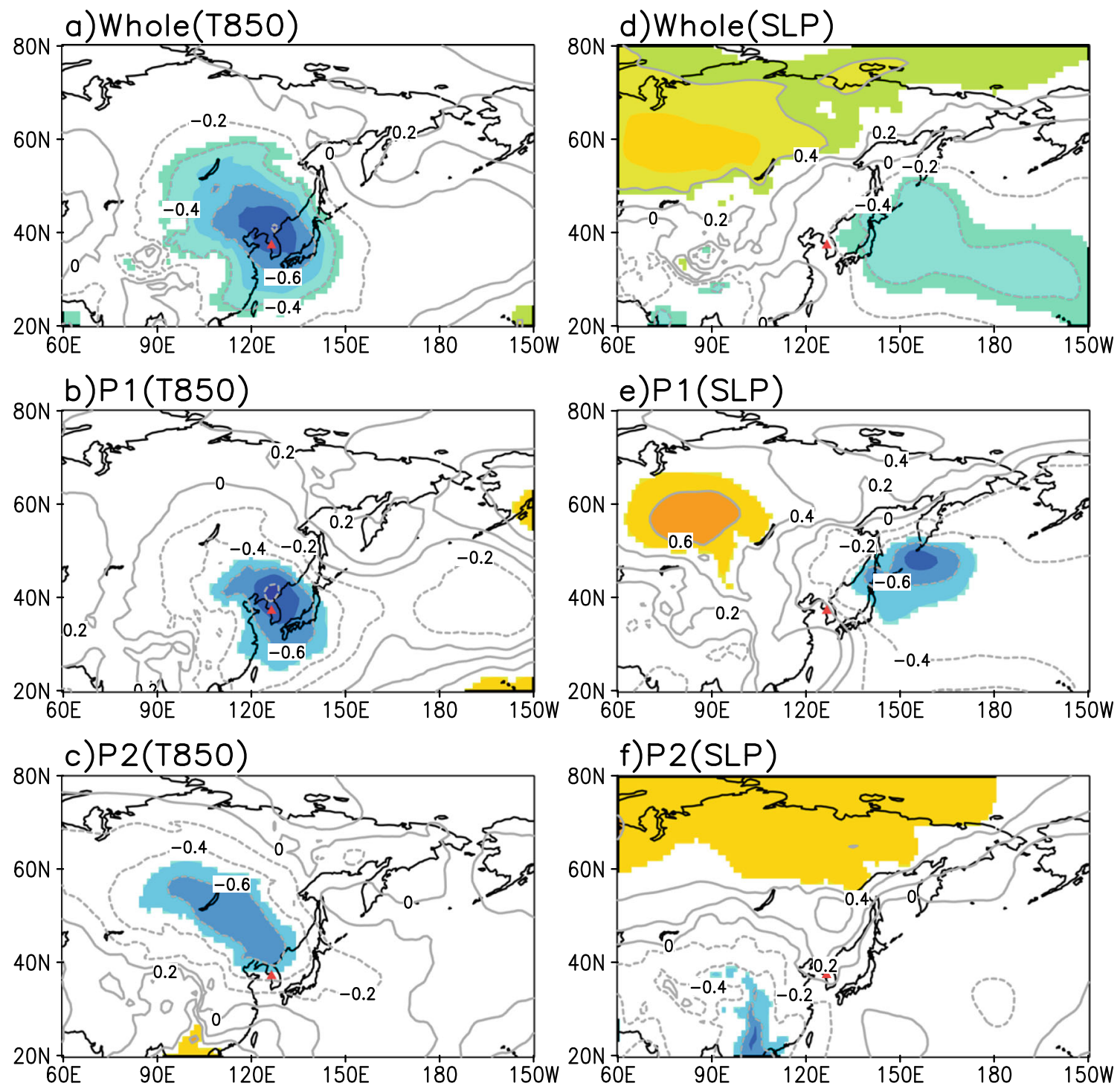

Fig. 6 Correlation coefficient between the number of cold nights in Seoul and (a-c) 850-hPa temperature anomalies and (d-f) SLP anomalies for (top) the whole analysis period, (middle) $\mathrm{P} 1$ and (bottom) $\mathrm{P} 2$ periods. The

values that are statistical significant at the $99 \%$ confidence level are shaded. Red triangle denotes Seoul

accompanied by an east-west dipolar SLP pattern with an anticyclonic circulation in Northern China and a cyclonic circulation in the western North Pacific. This feature induces strong northerlies around Korea, causing cold night events. In contrast, the P2 cold night events are characterized by a north-south dipolar pattern with a strong anomalous anticyclone over Siberia that has a quasi-barotropic structure. Correlation analysis confirms that the influence of the atmospheric circulation over the western North Pacific on the number of cold night events became weaker during this period. Consistent with this finding, the interannual correlation between the Pacific-related climatic indices, including
NPI, PDOI, PNAI, and WPI, and the number of cold night events are substantially reduced from P1 to P2.

These results, however, do not reveal a causal relationship. It is still unclear what caused the weakened influence of the western North Pacific circulation and how this affected the decadal change of the number of cold nights in Korea. To better understand the decadal variability of cold night events in Korea, it would be helpful to compare these results with those from neighboring countries as well. Whether a similar change in the late 1980s is observed in China or Japan is an interesting question. To establish a concrete causal relationship, climate modeling would be also useful. 
Fig. 7 a Correlation coefficients between the number of cold nights in Seoul and climate variability indices for the whole analysis period (black), P1 (blue) and P2 (red) periods. Single and double asterisks indicate statistical significant values at the $95 \%$ and $99 \%$ confidence levels, respectively. See Table 1 for the definition of each climate variability index. b, $\mathbf{c}$ Timeseries of the number of cold nights in Seoul and climate indices. Only EAWMI, SHI, and Pacific-related climate indices are shown

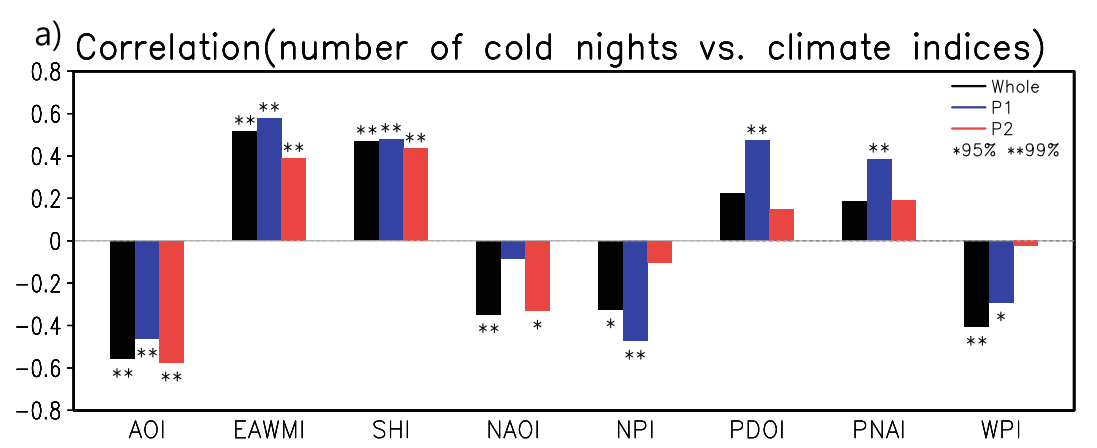

b)

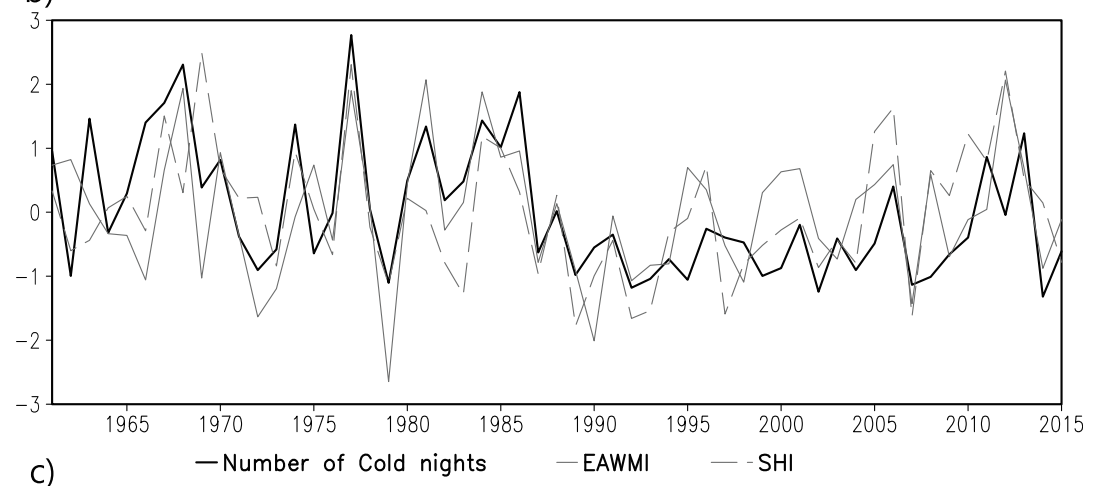

c)

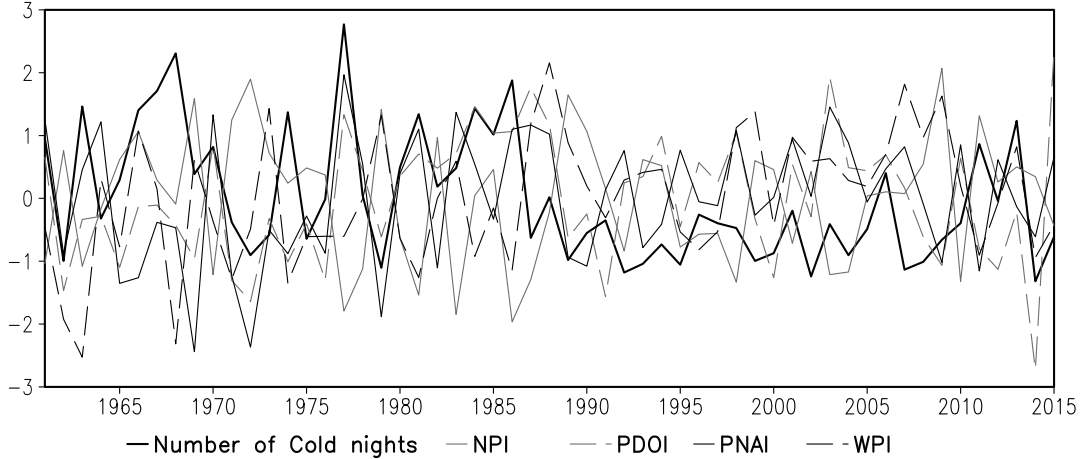

Acknowledgement This work was funded by the Korea Meteorological Administration Research and Development Program under Grant KMI(2018-01011).

\section{References}

Alexander, L.V., et al.: Global observed changes in daily climate extremes of temperature and precipitation. J. Geophys. Res. 111(D5), D05109 (2006). https://doi.org/10.1029/2005JD006290

Ansari, A.R., Bradley, R.A.: Rank-sum tests for dispersions. Ann. Math. Stat. 31(4), 1174-1189 (1960). https://doi.org/10.1214/aoms/ 1177705688

Choi, G., Kim, J.: Synoptic climatic patterns for winter extreme low temperature events in the Republic of Korea. J. Korean Geogr. Soc. 50, 1-21 (2015)

Choi, G., Kwon, W.-T., Boo, K.-O., Cha, Y.-M.: Recent spatial and temporal changes in means and extreme events of temperature and precipitation across the Republic of Korea. J. Korean Geogr. Soc. 43(5), 681-700 (2008)
Choi, J.-W., Cha, Y., Kim, J.-Y., Park, C.-H.: Interdecadal changes in the number of days on which temperature are not higher than $-5^{\circ} \mathrm{C}$ in winter in Seoul. J. Climate. Chang. Res. 7(1), 49-57 (2016). https://doi.org/10.15531/ksccr.2016. 7.1.49

Fischer, T., Gemmer, M., Liu, L., Su, B.: Change-points in climate extremes in the Zhujiang River Basin, South China, 1961-2007. Climatic Chang. 110(3-4), 783-799 (2012). https://doi.org/10. 1007/s10584-011-0123-8

Franzke, C.: A novel method to test for significant trends in extreme values in serially dependent time series. Geophys. Res. Lett. 40(7), 1391-1395 (2013). https://doi.org/10.1002/ grl.50301

Heo, I.H., Lee, S.-H.: Changes of unusual temperature events and their controlling factors in Korea. J. Korean Geogr. Soc. 41, 94-105 (2006)

Im, E.S., Ahn, J.-B.: Analysis of relationship between Korean winter temperature variability and global circulation indices. Asia-Pacific J. Atmos.Sci. 40, 441-452 (2004)

IPCC.: Managing the Risks of Extreme Events and Disasters to Advance Climate Change Adaptation. A Special Report of Working Groups I and II of the Intergovernmental Panel on Climate Change. In: Field, 
C.B., Barros, V., Stocker, T.F., Qin, D., Dokken, D.J., Ebi, K.L., Mastrandrea, M.D., Mach, K.J., Plattner, G.-K., Allen, S.K., Tignor, M., Midgley, P.M. (eds.). Cambridge University Press, p. $582(2012)$

Jhun, J.-G., Lee, E.-J.: A new East Asian winter monsoon index and associated characteristics of the winter monsoon. J. Climate. 17(4), 711-726 (2004). https://doi.org/10.1175/1520-0442(2004) 017<0711:ANEAWM>2.0.CO;2

Kiktev, D., Sexton, D. M., Alexander, L., Folland, C. K.: Comparison of modeled and observed trends in indices of daily climate extremes. J. Clim. 16, 3560-3571 (2003). https://doi.org/10.1175/15200442(2003)016<3560:COMAOT>2.0.CO;2

Kim, S.-W., Song, K., Kim, S.-Y., Son, S.-W., Franzke, C.: Linear and nonlinear trends of extreme temperatures in Korea. Atmosphere. 24(3), 379-390 (2014). https://doi.org/10. 14191/Atmos.2014.24.3.379

Kim, Y.-H., Kim, M.-K., Lau, W., Kim, K.-M., Cho, C.-H.: Possible mechanism of abrupt jump in winter surface air temperature in the late 1980s over the Northern Hemisphere. J. Geophys. Res. 120(24), 12474-12485 (2015). https://doi.org/10.1002/2015JD023864

Kim, Y.-H., Min, S.-K., Zhang, X., Zwiers, F.W., Alxander, L.V., Donat, M.G., Tung, Y.-S.: Attribution of extreme temperature changes during 1951-2010. Climate Dyn. 46, 1769-1782 (2016). https://doi.org/ 10.1007/s00382-015-2674-2

Kwon, M.-H., Jhun, J.-G., Wang, B., Ahn, S.-I., Kug, J.-S.: Decadal change in relationship between east Asian and WNP summer monsoons. Geophys. Res. Lett. 32(16), L16709 (2005). https://doi.org/ 10.1029/2005GL023026

Lee, K., Sung, J.-H., Kim, Y.-O., Lee, S.: Change-point analysis of mean temperature and extreme temperature in the Republic of Korea. J. Korean Geogr. Soc. 46(5), 583-596 (2011)

Lee, M.-H., Ho, C.-H., Kim, J., Song, C.-K.: Assessment of the changes in extreme vulnerability over East Asia due to global warming. Climatic Chang. 113(2), 301-321 (2012). https://doi.org/10.1007/ s10584-011-0345-9

Lee, K., Baek, H.-J., Cho, C.: Analysis of changes in extreme temperatures using quantile regression. Asia-Pac J. Atmos. Sci. 49(3), 313323 (2013a). https://doi.org/10.1007/s13143-013-0030-1

Lee, S.-S., Kim, S.-H., Jhun, J.-G., Ha, K.-J., Seo, Y.-W.: Robust warming over East Asia during the boreal winter monsoon and its possible causes. Environ. Res. Lett. 8, 034001 (2013b). https://doi. org/10.1088/1748-9326/8/3/034001

Lepage, Y.: A combination of Wilcoxon's and Ansari-Bradley's statistics. Biometrika. 58(1), 213-217 (1971). https://doi.org/10.1093/biomet/ 58.1.213

Mann, H.-B., Whitney, D.R.: On a test of whether one of two random variables is stochastically larger than the other. Ann. Math. Stat. 18(1), 50-60 (1947)

Min, S.-K., Zhang, X., Zwiers, F., Shiogama, H., Tung, Y.-S., Wehner, M.: Multimodel detection and attribution of extreme temperature changes. J. Clim. 26, 7430-7451 (2013). https://doi.org/10.1175/ JCLI-D-12-00551.1

Min, S.-K., et al.: Changes in weather and climate extremes over Korea and possible causes: A review. Asia-Pac J. Atmos. Sci. 51(2), 103121 (2015). https://doi.org/10.1007/s13143-015-0066-5

Moberg, A., et al.: Indices for daily temperature and precipitation extremes in Europe analyzed for the period 1901-2000. J. Geophys. Res. 111, D22106 (2006). https://doi.org/10.1029/2006JD007103

Onogi, K., et al.: The JRA-25 Reanalysis. J. Meteor. Soc. Japan. 85(3), 369-432 (2007). https://doi.org/10.2151/jmsj.85.369

Panagiotopoulos, F., Shahgedanova, M., Hannachi, A., Stephenson, D.B.: Observed trends and teleconnections of the Siberian High: A recently declining center of action. J. Climate. 18(9), 1411-1422 (2005). https://doi.org/10.1175/JCLI3352.1

Qian, W., Lin, X., Zhu, Y., Xu, Y., Fu, J.: Climatic regime shift and decadal anomalous events in China. Climatic Chang. 84(2), 167189 (2007). https://doi.org/10.1007/s10584-006-9234-z

Ryoo, S.-B., Kwon, W.-T., Jhun, J.-G.: Characteristics of wintertime daily and extreme minimum temperature over South Korea. Int. J. Climatol. 24(2), 145-160 (2004). https://doi.org/10.1002/joc.990

Yang, S., Feng, J., Dong, W., Chou, J.: Analyses of extreme climate events over China based on CMIP5 historical and future simulations. Adv. Atmos. Sci. 31(5), 1209-1220 (2014). https://doi.org/ 10.1007/s00376-014-3119-2

Zhang, X., Lu, C., Guan, Z.: Weakened cyclones, intensified anticyclones and recent extreme cold winter weather events in Eurasia. Environ. Res. Lett. 7(4), 044044 (2012). https://doi.org/10.1088/1748-9326/ $7 / 4 / 044044$

Publisher's Note Springer Nature remains neutral with regard to jurisdictional claims in published maps and institutional affiliations. 